\title{
BUKU DODING HALELUYA SEBAGAI SALAH SATU MEDIA PELESTARIAN LAGU RAKYAT SIMALUNGUN

\author{
DI GKPS SIMALINGKAR
}

\author{
Febri Ridho Sipayung \\ Prodi Pendidikan Musik
}

\begin{abstract}
This study aims to find out what folk song title Simalungun in Doding book Hallelujah, how is the form of the folk songs and the effectiveness of its conservation through replacement method lyrics/poems for the congregation GKPS Simalingkar.

This study is based on the theoretical foundation to explain the meaning of Hallelujah Doding Books, Media, Preservation, and Folk Songs Simalungun

The method used is descriptive qualitative. The population in this study are all Simalungun folk songs that are in the book Hallelujah Doding the 36 songs and 10 congregations GKPS Simalingkar. The techniques of Data collection in this study conducted by field observations, literature studies, interviews and documentations.

Generally, this research shows that the contribution of 36 folk songs in the book Doding Simalungun Hallelujah create varied impressions in the book. as well as with the form of songs that mostly consists of two parts. And look also the effectiveness of the preservation of the folk song lyrics Simalungun with replacement method/lyrics towards more religious make Hallelujah Doding books as one of the media in the preservation of the folk song Simalungun GKPS Simalingkar.
\end{abstract}

Keywords: Hallelujah Doding Books, Media Preservation, Folk Songs Simalungun 


\section{PENDAHULUAN}

Sumatera Utara merupakan

Provinsi yang memiliki beraneka ragam suku bangsa, mulai dari suku Batak Toba, Simalungun, Karo, Pakpak, Mandailing, Jawa, Nias, Melayu dan lain-lain. Masing-masing suku memiliki bermacam-macam kebudayaan dan tradisi yang berbeda-beda pula, baik di bidang musik, tari, adat istiadat, dan lain sebagainya. Lagu atau musik dari setiap daerah yang ada di Sumatera Utara selalu didendangkan, baik dalam upacara adat, pesta budaya, kelahiran, perkawinan, kematian, hiburan dan lain sebagainya.

Suku Simalungun merupakan salah satu bagian dari lima sub etnis batak yang ada di Sumatera Utara. Suku Simalungun memiliki ragam budayanya masing-masing baik dari lagu rakyat/daerah, musik daerah maupun tarian daerah.

Suku Simalungun mempunyai banyak akar budaya keseniannya salah satunya adalah lagu-lagu rakyat/daerah yang erat mengikat kehidupan masyarakat Simalungun itu sendiri dalam beraktifitas setiap hari. Lagu rakyat ini sangat dipengaruhi dengan keadaan lingkungan setempat dan pekerjaan mayoritas masyarakat Simalungun itu sendiri yang kebanyakan bertani. Lagu-lagu itu sering didengungkan saat mereka akan mulai bekerja di Juma (ladang) ataupun pesta panen dan lain sebagainya. Sebagai contoh sebut saja lagu Marsialop ari (gotong-royong) yang digunakan sebagai lagu pengiring tarian Haroan Bolon yang makna lagunya bersama sama bekerja diladang bergotong 
royong dan bercocok tanam yang merupakan mayoritas pekerjaan masyarakat di Simalungun.

$\begin{aligned} \text { Lagu } & \text { rakyat Simalungun } \\ \text { merupakan } & \text { salah satu aset } \\ \text { masyarakat } & \text { Simalungun dibidang }\end{aligned}$
kesenian daerah. Di zaman sekarang ini sangat jarang lagu-lagu rakyat Simalungun diperdengarkan karena mungkin pelestarian dari lagu rakyat dulu terkendala masalah teknologi yang belum adanya studio rekaman seperti zaman sekarang ini. Dampaknya Generasi muda Simalungun sekarang sulit mencari referensi mengenai lagu-lagu rakyat/daerah Simalungun itu sendiri untuk dipelajari.

Minimnya referensi tentang lagu rakyat Simalungun sangat berpengaruh dalam hal pembelajaran terlebih khusus terhadap generasi muda suku Simalungun. Terlepas dari minimnya referensi untuk belajar, sepertinya GKPS secara nyata memberikan sumbangsih melalui buku Doding Haleluya yang dipakai sebagai buku panduan bernyanyi jemaatnya didalam ibadah kebaktian setiap minggunya. Di dalam buku itu tampak jelas tidak sedikit lagu rakyat Simalungun yg diadaptasi dan diganti lirik/syairnya tetapi tetap menggunakan melodi utama lagu rakyat tersebut.

Untuk mengetahui lebih dalam, penulis merasa tertarik untuk melakukan suatu penelitian ilmiah yang memfokuskan tulisan ini pada Buku Doding Haleluya, dengan judul "BUKU DODING HALELUYA SEBAGAI SALAH SATU MEDIA PELESTARIAN LAGU RAKYAT SIMALUNGUN DI GKPS SIMALINGKAR".

\section{Tujuan Penelitian}


1. Untuk mengetahui judul lagu rakyat Simalungun yang ada didalam BUKU DODING

\section{HALELUYA}

2. Untuk mengetahui bentuk lagu rakyat Simalungun yang ada didalam BUKU DODING HALELUYA

3. Untuk mengetahui efektifitas pelestarian lagu rakyat Simalungun terhadap jemaat GKPS Simalingkar melalui penggantian lirik yang ada didalam BUKU DODING HALELUYA

\section{Landasan Teoritis}

Untuk membahas tentang isi dalam skripsi ini penulis memakai Teori Bentuk Lagu, Pengertian Doding, Pengertian Buku Doding Haleluya, Teori Media, Pengertian Pelestarian, dan Pengertian Lagu Rakyat.

\section{Lokasi dan Waktu Penelitian}

Penelitian ini akan dilaksanakan di GKPS Simalingkar. Waktu yang digunakan dalam pelaksanaan penelitian ini dimulai dari bulan November 2016Desember 2016.

\section{Populasi dan Sampel}

\section{Populasi}

Populasi dalam penelitian adalah seluruh lagu rakyat Simalungun yang ada didalam Buku Doding Haleluya yang berjumlah 36 lagu, dan 186 orang jemaat GKPS Simalingkar.

\section{Sampel}

Sampel dalam penelitian ini adalah 10 lagu rakyat simalungun yang populer dari 36 lagu rakyat Simalungun yang ada didalam Buku Doding Haleluya dan 10 orang Jemaat GKPS Simalingkar.

\section{Teknik Pengumpulan Data}

1. Observasi 
Untuk melakukan suatu penelitian peneliti wajib melakukan tata cara yang sudah ditetapkan, salah satunya adalah dengan observasi ke lapangan.

Penelitian yang dilakukan di lapangan adalah dengan pengamatan terlihat ataupun secara langsung, agar peneliti dapat mengamati serta memahami penggunaan Buku Doding Haleluya Sebagai Salah Satu Media Pelestarian Lagu Rakyat Simalungun di GKPS Simalingkar.

2. Wawancara

Penulis melakukan wawancara secara langsung dengan 10 jemaat GKPS Simalingkar Mengenai efektivitas pelestarian lagu rakyat Simalungun melalui penggantian lirik/lagu di dalam buku Doding Haleluya

3. Dokumentasi
Adapun dokumentasi yang dimaksudkan oleh peneliti disini dapat berupa gambar dan rekaman kegiatan yang dapat membantu untuk memperlihatkan kegiatan-kegiatan yang dilaksanakan, lokasi penelitian dan proses selama penelitian berlangsung, serta dalam proses pengolahan data.

bentuk dokumentasi yang dilakukan peneliti adalah pemotretan, audio visual,

\section{Studi Kepustakaan}

Pengumpulan data berdasarkan skripsi, buku-buku yang digunakan penulis yang berkaitan dan mendukung penelitian.

\section{Teknik Analisis Data}

Teknik pengumpulan data di atas diarahkan melalui analisis data deskriptif kualitatif untuk menjelaskan Buku Doding Haleluya Sebagai Salah Satu Media 
Pelestarian Lagu Rakyat Simalungun

Di GKPS Simalingkar.

ISI

Gambaran Umum GKPS

\section{Simalingkar}

GKPS Simalingkar beralamat

di Jalan Sagu Raya no 27 Perumnas

Simalingkar Medan. Gereja ini memiliki luas tanah secara keseluruhan $1964 \mathrm{M}^{2}$ yang diatasnya terdiri dari bangunan fisik gereja, gedung sekolah minggu, rumah penjaga gereja, juma tambar (ladang tanaman) dan lahan untuk parkir kendaraan. Tercatat sampai saat ini per tanggal 31 Desember 2016 jemaat yang ada di GKPS Simalingkar telah mencapai 735 jiwa yang terdiri dari 186 kepala keluarga.
Judul Lagu Rakyat Simalungun yang ada didalam Buku Doding Haleluya.

Berdasarkan hasil penelitian
yang sudah dilakukan penulis
terhadap judul lagu rakyat
Simalungun yang ada di dalam buku Doding Haleluya, terdapat sekitar 36 lagu rakyat Simalungun yang ada didalam buku tersebut yaitu, Dengan Pantun, Manduda, Inggou Sarunei, Ledangni Pining Ai, Mariah Sibahuei, Odak-Odak, Serma Dengan-Dengan, Alo Sideiding, Ajimbo-Ajimbo, Lai Luya, Mariah Judi Porang, Dengan pantun, Horas Ganup, Habangle- Habangle, Dengan Pantun, Poltak Ma Bittang, Doding Marorot, Inggou Sarunei, Haporas $\mathrm{Ni}$ Silokkung, Inggou Sarunei, Pining Anjei, Sitalasari, Gunung Kehen Ge Huluan, Marondang Mariling-Iling, Ija Juma 
Tidahan, Pining Batis, Dengan

Pantun, Manogu Losung, Dengan

Pantun, Dengan Pantun, Urdo-Urdo

(hurma lo dayok), Sidalit Panou,

Aloya-Aloya Da, Toloi Katipang,

Parlimbou, Ilah Bolon.

Bentuk Lagu Rakyat Simalungun

yang ada didalam Buku Doding

\section{Haleluya.}

Dari 36 lagu rakyat

Simalungun yang tertera diatas

penulis akan mengkaji bentuk lagu

dengan menggunakan analisis frase

dan motif. Akan tetapi dikarenakan

keterbatasan penulis dalam mengkaji

semua bentuk lagu rakyat

Simalungun yang terdapat didalam

buku Doding Haleluya, maka penulis

hanya mengambil sepuluh sampel

lagu dari 36 lagu rakyat Simalungun

yang ada didalam buku tersebut.

Adapun ke 10 lagu yang diangkat

adalah Sitalasari, Serma Dengan-
Dengan, Mariah Sibahuei, Ija Juma

Tidahan, Haporasni Silokkung,

Manduda, Pining Anjei, Urdo-Urdo,

Odak-Odak, Ilah Bolon.

Dari hasil pengkajian bentuk lagu rakyat Simalungun yang ada didalam buku Doding Haleluya melalui analisis Frase dan Motif didapatkan kesimpulan bahwa kebanyakan lagu rakyat Simalungun yang ada didalam buku Doding Haleluya terdiri dari Bentuk lagu 2 Bagian (AB)

Efektifitas Pelestarian Lagu

Rakyat Simalungun Terhadap Jemaat GKPS Simalingkar

Melalui Penggantian Lirik Lagu Yang Ada di Dalam Buku Doding Haleluya

Untuk melihat seberapa efektifkah pelestarian lagu rakyat Simalungun melalui metode penggantian lirik/syair lagu yang ada di dalam buku Doding Haleluya, 
penulis melalukan wawancara dengan 10 orang jemaat GKPS Simalingkar yang terdiri dari perwakilan Seksi-seksi didalam gereja.

\section{Dari keseluruhan hasil} wawancara yang telah dilakukan dapat diambil kesimpulan bahwasanya pelestarian lagu rakyat Simalungun melalui metode penggantian Lirik/Syair terhadap Jemaat GKPS Simalingkar dirasakan sangat efektif dengan anggapan ketika jemaat menyanyikan salah satu dari lagu rakyat tersebut pasti langsung teringat dengan lagu rakyat Simalungun yang biasa didendangkan pada acara-acara pesta adat Simalungun atau acara Marsombuh Sihol (Melepas Rindu).

Dalam segi popularitas lagu rakyat Simalungun yang ada didalam buku Doding Haleluya, lagu rakyat Serma Dengan-dengan (Hosianna ma bai Raja na Roh) menjadi lagu yang paling populer bagi jemaat GKPS Simalingkar. Adapun data tersebut didapat dari wawawancara secara terbuka dengan 10 orang jemaat yang menjawab lagu Serma Dengan-dengan (Hosianna ma Bai Raja na Roh) 7 Orang, Ilah Bolon (Panorang Olob-olob) 2 Orang, Sitalasari (Marmalas Uhur) 1 Orang. Hal tersebut tidak terlepas dari seringnya lagu-lagu tersebut dinyanyikan didalam kebaktian umum di GKPS Simalingkar.

Dari data-data tersebut terlihat bagaimana mayoritas jemaat GKPS Simalingkar yang diwawancarai sangat terbuka dalam menjawab pertanyaan-pertanyaan yang diajukan, sehingga suasana tidak terlalu kaku dan jawaban yang diberikan pun sangat alami dan apa adanya. Harapan kedepannya pelestarian lagu rakyat Simalungun 
melalui buku Doding Haleluya di

GKPS Simalingkar sangat

diharapkan jemaat GKPS

Simalingkar terus menerus harus

dilakukan, tidak hanya pada

kebaktian umum saja, diharapkan

pada Partonggoan (kebaktian

dirumah jemaat) sudah harus dimulai

penggunaan lagu rakyat Simalungun.

\section{PENUTUP}

\section{Kesimpulan}

Berdasarkan hasil penelitian dan pembahasan yang telah diuraikan pada bab sebelumnya, maka peneliti membuat kesimpulan sebagai berikut:

1. Jumlah lagu rakyat Simalungun yang ada di dalam buku Doding Haleluya berjumlah sebanyak 36 lagu, berikut adalah Judul lagulagu rakyat Simalungun yang ada di dalam buku Doding
Haleluya adalah Dengan

Pantun, Manduda, Inggou

Sarunei, Ledangni Pining Ai,

Mariah Sibahuei, Odak-

Odak, Serma Dengan-

Dengan, Alo Sideiding,

Ajimbo-Ajimbo, Lai Luya,

Mariah Judi Porang, Dengan

pantun, Horas Ganup,

Habangle- Habangle,

Dengan Pantun, Poltak Ma

Bittang, Doding Marorot,

Inggou Sarunei, Haporas Ni

Silokkung, Inggou Sarunei,

Pining Anjei, Sitalasari,

Gunung Kehen Ge Huluan,

Marondang Mariling-Iling,

Ija Juma Tidahan, Pining

Batis, Dengan Pantun,

Manogu Losung, Dengan

Pantun, Dengan Pantun,

Urdo-Urdo (hurma lo dayok),

Sidalit Panou, Aloya-Aloya 
Da, Toloi Katipang,

Parlimbou, Ilah Bolon.

2. Dari hasil pengkajian bentuk lagu rakyat Simalungun yang ada didalam buku Doding Haleluya melalui analisis Frase dan Motif didapatkan kesimpulan bahwa kebanyakan lagu rakyat Simalungun yang ada didalam buku Doding Haleluya terdiri dari Bentuk lagu 2 Bagian $(\mathrm{AB})$

3. Pelestarian lagu rakyat Simalungun melalui metode penggantian lirik/syair lagu terhadap jemaat GKPS Simalingkar dirasakan sangat efektif dengan anggapan ketika mendengar lagu tersebut mayoritas mengatakan langsung teringat dengan lagu rakyat Simalungun tertentu yang biasa didengar didalam acara pesta adat Simalungun atau acara Marsombuh Sihol

4. Dari ke 36 lagu rakyat Simalungun yang ada didalam buku Doding Haleluya lagu Serma Dengan-dengan (Hosianna ma bai Raja na Roh) menjadi lagu yang paling populer bagi jemaat GKPS Simalingkar.

5. Dari ke 36 lagu rakyat Simalungun yang ada didalam buku Doding Haleluya ada sebagian lagu yang telah disederhanakan notasinya untuk memudahkan pengucapannya didalam bernyanyi.

\section{Saran}

Berdasarkan kesimpulan yang telah diuraikan, maka peneliti 


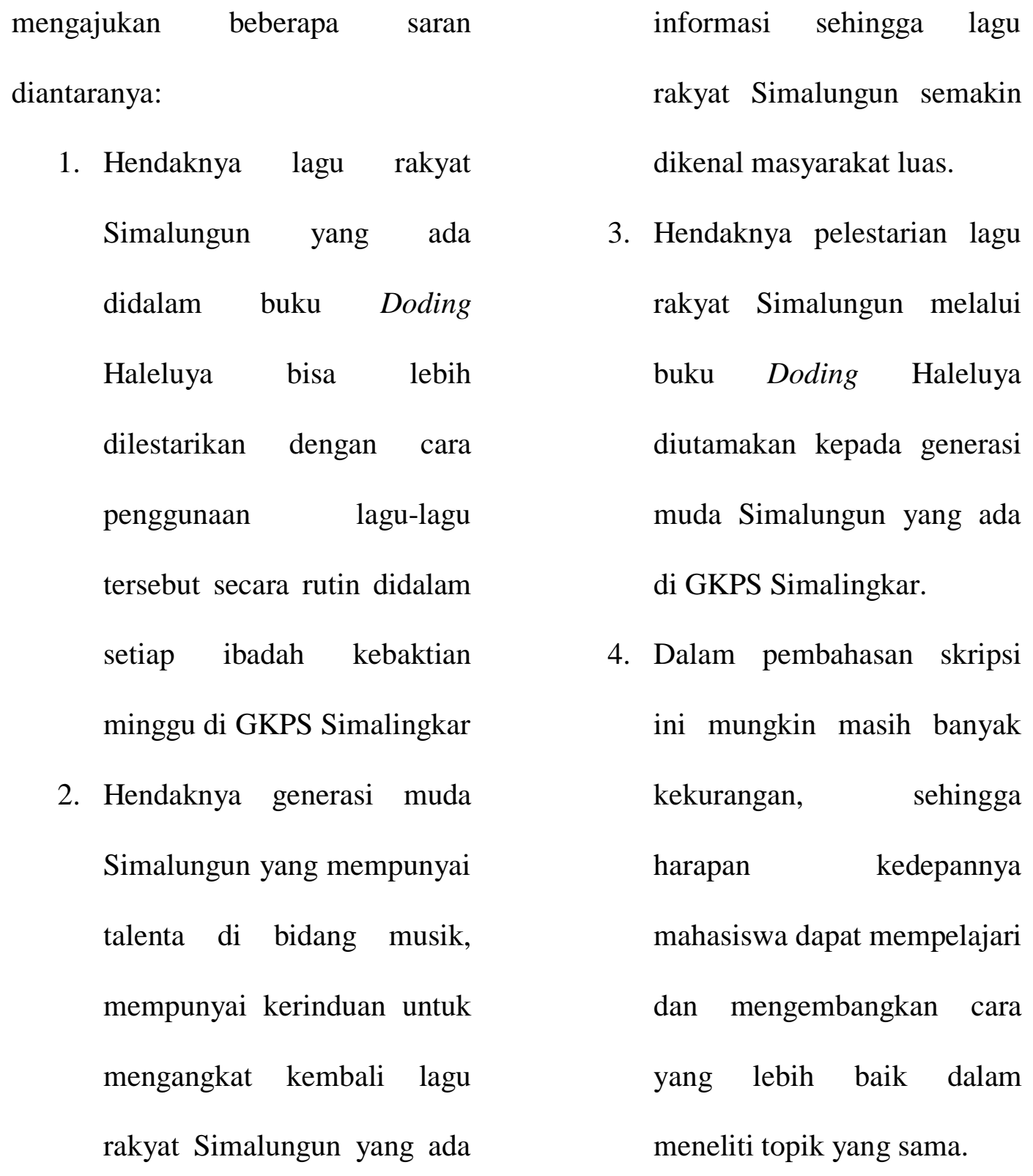

didalam buku Doding

Haleluya melalui aransemen

\section{DAFTAR PUSTAKA}

musik yang baru dengan tidak

menghilangkan makna khas

Banoe, P. 2003. Kamus Musik, Yogyakarta: Kanisius

lagu rakyat tersebut dan

Damanik, Jan J. 2012. Dari Ilah menggunakan media sosial Menuju Allah, Yogyakarta: ANDI

sebagai sarana penyampaian 
Danandjaja, J. 1984. Folklore Indonesia. Jakarta: Pustaka Grafiti

Edmund Prier Sj, Karl. 2004. Ilmu Bentuk Musik. Yogyakarta: Pusat Musik Liturgi

Japi Tambayong, Ensiklopedia Musik Jilid I, Jakarta: PT Cipta Api Pustaka, 1992

Maryaeni,2005. Metode Penelitian Kebudayaan, Jakarta: Bumi Aksara

Pimpinan Pusat GKPS, 2013. Visi Dan Misi GKPS 2011-2030, P.Siantar: Kolportase GKPS

Purba, Jan Riwando, Perangkat Alat Musik Simalungun dan Kontekstualisasi Musik Gerejani (Suatu

Tinjauan Dogmatis-Teologis Terhadap Penggunaan Perangkat Alat Musik Tradisional Simalungun dalam Ibadah dan Upaya Pengkontekstualisasi Musik Gereja Bernuansa Simalungun) STT Abdi Sabda, 2013

Purba, Rudolf, Saragih, J. E. 2012. Peradaban Simalungun: Intisari Seminar Kebudayaan Simalungun se-Indonesia Pertama Tahun 1964, P.Siantar: Komite Penerbit Buku-Buku Simalungun
Purba, Setia Dermawan. 2008. Nyanyian Anak Dalam Kebudayaan Etnik Simalungun Dalam Etnomusikologi, Medan: Universitas Sumatera Utara

Sitanggang,Radesman.2014.

Orientasi Nilai Budaya Folklore Etnik Simalungun Pematang Siantar: L-SAPA

Sukmadinata, Syaodih.2009. Metode Penelitian Pendidikan. Bandung: PT. Remaja Rosdakarya

Sumbayak Minaria S. dan Jaiman Sumbayak, "In Memoriam Pdt. J. Wismar Saragih 7 Maret 1968 - 7 Maret 2007 "

Sugiyono.2008. Metode Penelitian Pendidikan. Alfabeta: Bandung

Sugiyono.2012. Metode Penelitian kuantitatif kualitatif dan $R \& B$. Alfabeta: Bandung

(1987-1988). Ensiklopedia Indonesia Edisi Khusus. Jakarta: PT. Internusa

\section{SUMBER INTERNET}

http://www.academia.edu/10356103/ Nyanyian

https://pmtagkps.wordpress.com/201 6/02/25/sejarah-singkat-gkps-dan- 
perjumpaannya-dengan-budaya-

simalungun/

http://duniaberita.top/buku-doding-

haleluya/

https://dodinghaleluya.wordpress.co

$\mathrm{m} /$ 